\title{
Experimental Study on Series-Parallel Grouping Inconsistency of Zinc-Nickel Single Flow Batteries
}

\author{
Shouguang Yao ${ }^{1, *}$, Xiaofei Sun ${ }^{1}$, Wei Liu ${ }^{1}$, Jie Cheng ${ }^{2}$, Yunhui Zhao ${ }^{1}$ \\ ${ }^{1}$ Jiangsu University of Science and Technology, Zhenjiang, 212003, China \\ ${ }^{2}$ Zhangjiagang Smartgrid Fanghua Electrical Energy Storage Research Institute Co., Ltd, \\ Zhangjiagang, 215600, China \\ *E-mail: zjyaosg@126.com
}

doi: $10.20964 / 2019.06 .40$

Received: 26 June 2018 / Accepted: 24 March 2019 / Published: 10 May 2019

\begin{abstract}
This study experimentally investigated the effects of the charge/discharge current, initial state of charge $(S O C)$, internal resistance, and initial nominal capacity on the performance characteristics and efficiency of series-parallel battery to address the inconsistency problems of zinc-nickel single flow battery during the use of battery pack energy storage system. Experimental results show that the differences in charge/discharge current, initial SOC, and initial capacity change the inconsistency of battery pack. The difference in initial nominal capacity is the most influential factor, whereas the charge/discharge current is the least influential factor. Meanwhile, the inconsistency of internal resistance increases, which enlarges the energy loss of the battery pack and increases the temperature. The optimum operating current is below $30 \mathrm{~A}$ and the optimum deviation in initial SOC is within 10\%, at which the inconsistency of the zinc-nickel single flow battery pack and the balance of the branch current are satisfactory.
\end{abstract}

Keywords: zinc-nickel single flow battery; series-parallel batteries; inconsistency; charge/discharge characteristics

\section{$\underline{\text { FULL TEXT }}$}

(C) 2019 The Authors. Published by ESG (www.electrochemsci.org). This article is an open access article distributed under the terms and conditions of the Creative Commons Attribution license (http://creativecommons.org/licenses/by/4.0/). 